\title{
Factors associated with survival in a large series of patients with malignant pleural mesothelioma in New South Wales
}

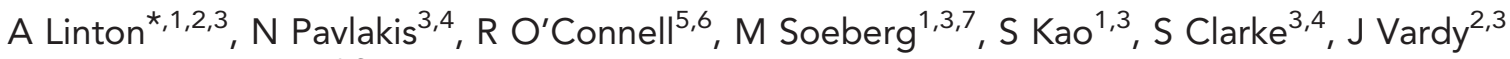 \\ and $\mathrm{N}$ van Zandwijk $\mathrm{k}^{1,3}$
}

\begin{abstract}
${ }^{1}$ Asbestos Diseases Research Institute (ADRI), University of Sydney, PO Box 3628, Rhodes, NSW 2139, Australia; ${ }^{2}$ Concord Cancer Centre, Sydney, Concord, NSW 2139, Australia; ${ }^{3}$ Sydney Medical School, University of Sydney, Sydney, Australia; ${ }^{4}$ Royal North Shore Hospital, St Leonards, NSW 2065, Australia; ${ }^{5}$ NHMRC Clinical Trials Centre, Camperdown, NSW 2050, Australia; ' ${ }^{6} y d n e y$ Cancer Centre, Camperdown, NSW 2050, Australia and ${ }^{7}$ Cancer Institute NSW, Alexandria, Sydney, NSW 1435, Australia
\end{abstract}

Background: Although the prognosis of most patients presenting with malignant pleural mesothelioma (MPM) is poor, a small proportion survives long term. We investigated factors associated with survival in a large patient series.

Methods: All patients registered with the NSW Dust Diseases Board (2002-2009) were included in an analysis of prognostic factors using Kaplan-Meier and Cox regression analysis. On the basis of these analyses, we developed a risk score (Prognostic Index (PI)).

Results: We identified 910 patients: $90 \%$ male; histology (epithelioid 60\%; biphasic 13\%; sarcomatoid 17\%); stage (Tx-IIII 48\%; III-IV 52\%); and calretinin expression (91\%). Treatment: chemotherapy (CT) 44\%, and extrapleural-pneumonectomy (EPP) 6\%. Median overall survival (OS) was 10.0 months. Longer OS was associated with: age $<70$ (13.5 vs 8.5 months; $P<0.001)$; female gender (12.0 vs 9.9 months; $P<0.001$ ); epithelioid subtype (13.3 vs 6.2 months; $P<0.001)$; ECOG status 0 (27.4 vs 9.7 months; $P=0.015)$, calretinin expression (10.9 vs 5.5 months; $P<0.001$ ); neutrophil-lymphocyte ratio (NLR) $<5$ (11.9 vs 7.5 months; $P<0.001$ ); platelet count $<400$ (11.5 vs 7.2 months; $P<0.001$ ); and normal haemoglobin (16.4 vs 8.8 months; $P<0.001$ ). On time-dependent analysis, patients receiving pemetrexed-based chemotherapy $(H R=0.83 ; P=0.048)$ or $E P P(H R=0.41 ; P<0.001)$ had improved survival. Age, gender, histology, calretinin and haematological factors remained significant on multivariate analysis. In all, $24 \%$ of patients survived $>20$ months: $16 \%$ of these receiving EPP, and $66 \%$ CT. The PI offered improved prognostic discrimination over one of the existing prognostic models (EORTC).

Conclusions: We identified calretinin expression, age, gender, histological subtype, platelet count and haemoglobin level as independent prognostic factors. Patients undergoing EPP or pemetrexed-based chemotherapy demonstrated better survival, but $84 \%$ and $34 \%$ of long survivors, respectively, did not receive radical surgery or chemotherapy.

Despite modest therapeutic advances in the past decade, the prognosis of malignant pleural mesothelioma (MPM), an aggressive cancer associated with previous asbestos exposure, remains grim (Linton et al, 2012). However, it has also been recognised that some MPM patients may survive substantially longer than the median survival time of 9-12 months (Vogelzang et al, 2003; Cao et al, 2010; Helland et al, 2012).
Evidence on factors associated with prolonged survival is largely drawn from studies investigating series of patients receiving chemotherapy or radical surgery. Analyses of pooled clinical trial data have demonstrated the prognostic impact of certain demographic variables (age and gender), clinical and pathological data (haemoglobin levels, leukocyte and platelet counts and performance status) and tumour characteristics (histological subtype)

*Correspondence: Dr A Linton; E-mail: anthony.linton@sydney.edu.au

Received 29 April 2014; revised 29 July 2014; accepted 7 August 2014; published online 4 September 2014

(c) 2014 Cancer Research UK. All rights reserved 0007-0920/14 
leading to the development of two scoring systems, one developed by the European Organisation for Research and Treatment of Cancer (EORTC) and the other by the Cancer and Leukaemia Group B (CALGB) (Curran et al, 1998; Herndon et al, 1998; Fennell et al, 2005; Meniawy et al, 2013). However, these systems do not include more recently identified prognostic factors, such as clinical stage at diagnosis (Abakay et al, 2013), hypo-albuminaemia (Murphy et al, 2013) and the neutrophil-lymphocyte ratio (NLR) (Kao et al, 2010; Kao et al, 2011). Non-randomised studies in MPM patients who received radical surgery revealed that clinical stage, histological subtype and the use of pemetrexed-based chemotherapy were associated with longer-term survival (Flores et al, 2008; Yan et al, 2011).

Here we report results from analyses of a database of all MPM patients diagnosed in 2002-2009 who received compensation for occupational exposure to asbestos in New South Wales, Australia. We assessed a range of demographic, clinical and pathological, tumour and treatment factors associated with longer-term survival in this large series of patients. In addition, we developed a risk score that may better identify patients likely to have longer survival.

\section{MATERIALS AND METHODS}

The Sydney Local Health District Ethics Committee approved this study.

Patient data. The Workers' Compensation Dust Diseases Board (DDB) collect comprehensive data on patients who contracted MPM as a result of their employment in New South Wales (NSW). It is estimated that this represents approximately $70 \%$ of all MPM cases recorded on the NSW Cancer Registry for the same period. We identified patients who registered with the DDB between 1 January 2002 to 31 December 2009 who had a confirmed diagnosis of MPM, based on detailed clinical, pathological, radiological and occupational histories. NSW death certificate data were linked to the DDB records. Mortality follow-up was ascertained up to 27 June 2012. Clinical and occupational histories were obtained from the DDB database. Where incomplete, missing data were sought from the treating physicians, surgeons and general practitioners.

Demographic data collected included sex, age at diagnosis, residential location at registration, smoking status, age at first asbestos exposure and occupational history. Residential location was classified according to the Australian Standard Geographical Classification-Remoteness Classification (Australian-Bureau-ofStatistics, 2011). We estimated cumulative years of occupational asbestos exposure using a patients' occupational history and their first age of asbestos exposure. Performance status was noted according to Eastern Cooperative Performance Group (ECOG) criteria and dichotomised according to EORTC prognostic classification (ECOG $0 v s \geqslant 1$ ) (Curran et al, 1998). Where not formally documented, patients were classified as $\geqslant 1$ when clinical symptoms (pain, dyspnoea, cough or lethargy) were recorded. Results of blood tests taken within 30 days of diagnosis, pathology reports (at the time of diagnosis or surgery) and radiological data (CT imaging to estimate clinical stage according to AJCCC criteria (Chahinian and Pass, 2000)) were reviewed.

Statistical analysis. The prognostic value of variables was first assessed using log-rank analysis and then with adjustment for other covariates in multivariable Cox regression models. Survival was defined as the time from diagnosis to death or the end of follow-up.

Time-dependent Cox regression modelling was employed to assess the effects of chemotherapy (pemetrexed and EPP), fitted as time-varying covariates, both in univariate analysis and with adjustment for important prognostic factors (fixed effects).
Prognostic factors were identified using a backward selection procedure. Only variables with $P<0.20$ in univariate analysis were included as candidate variables in the model selection procedure.

NLR was assessed as a continuous variable. The remaining continuous variables were dichotomised according to clinically relevant classification. Albumin and white cell count (WCC) were significant in univariate analysis but were omitted from the model due to a low number of available results for albumin and the relationship between WCC and NLR. Logistic regression was employed to identify predictors of long-term survival (survival double that of our median of 10 months (i.e., 20 months)).

To illustrate the impact of EPP, we utilised a proportional hazards model fitted to patients classified as good-prognosis according to EORTC prognostic scoring (in brief with two or less of the following characteristics: WBC $\geqslant 8.3 \times 10^{9} 1^{-1} ; \mathrm{ECOG} \geqslant 1$; histological diagnosis probable/possible; male gender; non-epithelioid histology) (Curran et al, 1998). Extended Kaplan-Meier estimates (Snapinn et al, 2005) were calculated and plotted. A sensitivity analysis of the effect of EPP was conducted using the landmark analysis (Freedman et al, 1992) for comparison with the time-dependent model results. A landmark time of 4 months was selected as the majority of EPP procedures were performed within the first 4 months. A Cox regression model was employed which assessed the effect of EPP within 4 months on survival from 4 months onwards. This method is based on non-randomised comparisons and only includes patients surviving to 4 months. In the subgroup analysis, a test for interaction in the Cox regression model was performed to ascertain whether the hazard ratio for the effect of EPP surgery on survival differed significantly between the various categories.

Finally, using Cox regression a points system (Prognostic Index (PI)) was developed by simplifying the computations of the multivariable risk model as per Sullivan et al (2004). The points system is a system that simplifies the computation of the $\sum \beta \mathrm{X}$ required to estimate risk from a Cox model. This is achieved by assigning integer points to each level of each risk factor so that a clinician can easily approximate $\sum \beta \mathrm{X}$ for a specific risk factor profile by summing integer points. The weighted points are determined by the relative magnitudes of the regression coefficients from Cox regression. The risk estimate is then determined from a reference table, which provides risk estimates for each point total. The points system is organised around categories designed to mirror clinically meaningful risk factor states. All available clinical and demographic information was considered to derive the new PI. The final model was based on a sample size of 551 patients. The discriminatory ability of the PI was measured by calculating $C$ statistics (identical to the area under the receiver operating characteristic (ROC) curve, ranging from 0 to 1 ). A Wilcoxon statistic (Hanley and McNeil, 1982; Hosmer and Lemeshow, 2000) was calculated, which provides the same quantity as that obtained by calculating the area under the corresponding ROC curve using the trapezoidal rule. This requires forming all possible pairs of events and non-events and counting pairs in which a risk index correctly orders the pair to derive the probability of a correct ranking. Ties are scored 0.5 . The association between the risk score and survival was compared with that of an existing scoring system (EORTC), which classifies patients into two groups: a goodprognosis group that corresponds to patients having $0-2$ poor prognostic factors; and a poor-prognosis group that have 3-5 unfavourable factors. For the purpose of this comparison, our new scoring system was dichotomised with receiver operating characteristic analysis used to determine the optimum risk score cutoff to predict 20-month survival.

For each scoring system, the two risk groups were compared for survival duration using the log-rank test and Cox model. Kaplan-Meier curves were constructed to compare survival probabilities. Additionally, separate Kaplan-Meier curves were 
constructed for each of the four groups formed from unique combinations of the EORTC score $(0-2,3+)$ and the new PI $(0-5,6+)$. A Cox model that included both indexes as explanatory variables was also fitted. We could not perform a comparison to the CALGB model due to the absence of key variables in retrospective records.

SAS software, version 9.3 (SAS Institute Inc., Cary, NC, USA) was used for the analysis. R 3.0.2 and STATA 13.0 (StataCorp, College Station, TX, USA) were used for the graphics.

\section{RESULTS}

Patient characteristics. Data on 1121 patients diagnosed with MPM were collected. Patients were excluded from our analyses if they resided (or received medical care) outside of NSW (17\%), had primary peritoneal disease $(<1 \%)$ or their basic clinical information was missing $(<1 \%)$. After applying these exclusion criteria, data on 910 patients were available for analyses representing $82 \%$ of patients registered at the DDB (Figure 1).

MPM patients were more likely to be male (90\%), elderly (median age of 72 years at diagnosis), live in a major city (66\%), have epithelioid histology (60\%) and have an ECOG status $\geqslant 1$ (85\%) (Table 1). Calretinin expression on immunohistochemistry (IHC) was available for $82 \%$ of patients, with $91 \%$ showing positive expression $(97.3 \%$ in epithelioid, $94.8 \%$ in biphasic, $60 \%$ in sarcomatoid). Clinical stage at diagnosis was available for $86 \%$ of patients, with $48 \%$ having early stage and 52\% advanced stage disease. In total, $41 \%$ of patients received chemotherapy: $93 \%$ of these received pemetrexed-based chemotherapy. Data concerning chemotherapy use were missing in $7 \%$ of patients. Chemotherapy utilisation increased from almost $39 \%$ to $49 \%$ during the study period as a likely consequence of the addition of pemetrexed to the Australian pharmaceutical benefits scheme (November 2007). There was no difference between chemotherapy usage in patients living in major cities in comparison to patients living in regional/ remote locations (41.5\% vs $40.7 \%$ ). Radical surgery, in the form of EPP, was undergone by $6.4 \%$ of the study population. Fifty-six of the $58(97 \%)$ of these operations were performed by a single surgeon. The 90-day mortality in this series was 3.5\%. Of those patients receiving EPP, 64\% underwent postoperative radiotherapy and $33 \%$ induction or adjuvant chemotherapy.

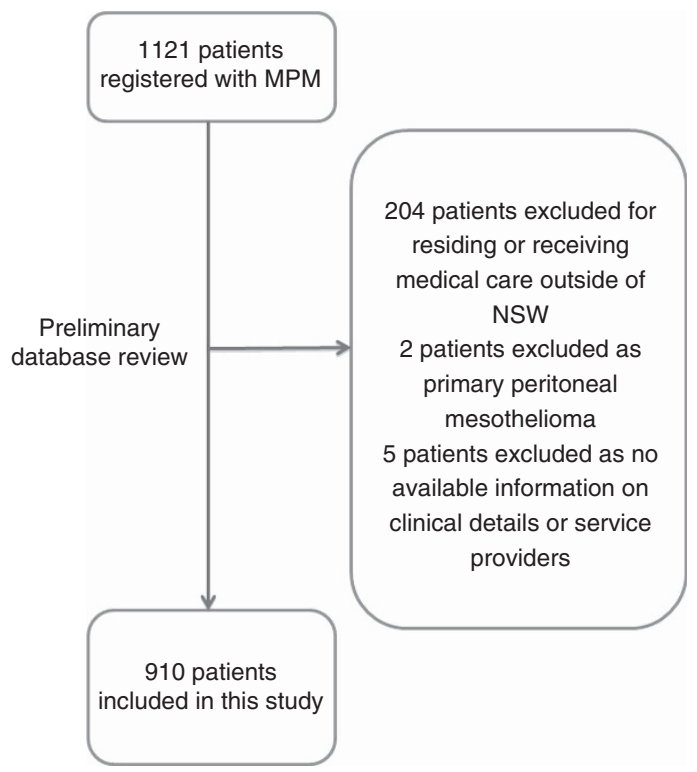

Table 1. Characteristics of patients diagnosed with malignant pleural mesothelioma compensated for occupational

asbestos exposure in New South Wales, 2002-2009 $(n=910)$, by patient characteristics

\begin{tabular}{|c|c|c|}
\hline & Number (value) & $\%$ \\
\hline \multicolumn{3}{|l|}{ Demographic characteristics } \\
\hline \multicolumn{3}{|l|}{ Sex } \\
\hline Male & 92 & 90 \\
\hline Female & 818 & 10 \\
\hline Median age at diagnosis & (72 years of age) & - \\
\hline \multicolumn{3}{|l|}{ Smoking status } \\
\hline Never smoker & 302 & 33 \\
\hline Ex/current smoker & 464 & 51 \\
\hline Missing status & 144 & 16 \\
\hline \multicolumn{3}{|l|}{ Asbestos exposure } \\
\hline Median age at first exposure & 18 years of age & - \\
\hline Median cumulative asbestos exposure ${ }^{a}$ & 24 years & - \\
\hline \multicolumn{3}{|l|}{ Geographic location at the time of diagnosis } \\
\hline Major city & 605 & 67 \\
\hline (Inner or outer) Regional & 302 & 33 \\
\hline Remote & 3 & $<1$ \\
\hline
\end{tabular}

Clinical and pathological characteristics

ECOG status

0

$\geqslant 1$

Missing

Calretinin expression

Positive expression

Negative expression

Testing not performed

Clinical stage at diagnosis ${ }^{b}$

Early stage disease (Stages X, I-II)

Late stage disease (Stages III-IV)

CT data not available

NLR

$<5$
$\geqslant 5$

$\geqslant 5$

Haemoglobin (from baseline)

$<1 \mathrm{~g} \mathrm{dl}^{-1}$

$\geqslant 1 \mathrm{~g} \mathrm{dl}^{-1}$

Missing

Platelets $\left(\times 10^{9} \mathrm{I}^{-1}\right)$

$<400$

$\geqslant 400$

Missing

Albumin

$\geqslant 35 \mathrm{~g} \mathrm{dl}^{-1}$

$<35 \mathrm{~g} \mathrm{dl}^{-1}$

Missing

White cell count

$<8.3$

$\geqslant 8.3$

Missing

|

14

14
776

776
120

\begin{tabular}{l|l}
120 & 85 \\
\hline
\end{tabular}

Tumour characteristics

Histological subtype

Epithelioid

Biphasic

Sarcomatoid

Missing values

\begin{tabular}{|c|c}
\hline 681 & 75 \\
64 & 7 \\
165 & 18 \\
\hline 377 & 42 \\
404 & 44 \\
129 & 14 \\
\hline 530 & 58 \\
316 & 35 \\
64 & 7 \\
\hline 211 & 23 \\
637 & 70 \\
62 & 7 \\
\hline 613 & 67 \\
232 & 26 \\
65 & 7 \\
\hline 382 & 42 \\
281 & 31 \\
247 & 27 \\
\hline 394 & 43 \\
453 & 50 \\
63 & 7 \\
\hline & \\
\hline
\end{tabular}

Treatment characteristics

Chemotherapy

Received chemotherapy

Received pemetrexed

Did not receive chemotherapy

Missing data

Surgery

Underwent EPP

Did not undergo EPP

Missing

$\%$

0

$<1$




\section{Table 1. (Continued)}

\begin{tabular}{|c|c|c|}
\hline & Number (value) & $\%$ \\
\hline $\begin{array}{l}\text { Radiotherapy } \\
\text { Adjuvant radiotherapy performed } \\
\text { Adjuvant radiotherapy not performed } \\
\text { Missing }\end{array}$ & $\begin{array}{r}37 \\
803 \\
71\end{array}$ & $\begin{array}{c}4 \\
88 \\
8\end{array}$ \\
\hline \multicolumn{3}{|l|}{ Outcome characteristics } \\
\hline Median overall survival & 10.0 months & - \\
\hline $\begin{array}{l}\text { EORTC Prognostic Score } \\
<3 \\
\geqslant 3 \\
\text { Missing }\end{array}$ & $\begin{array}{l}305 \\
468 \\
137\end{array}$ & $\begin{array}{l}- \\
34 \\
51 \\
15\end{array}$ \\
\hline \multicolumn{3}{|c|}{$\begin{array}{l}\text { Abbreviations: ECOG = Eastern Cooperative Oncology Group; EORTC = European Orga- } \\
\text { nisation for Research and Treatment of Cancer; EPP = extrapleural-pneumonectomy; } \\
\text { NLR = neutrophil-lymphocyte ratio. } \\
a^{a} \text { Estimated using data of a patients' first age at asbestos exposure and occupational history. } \\
{ }^{b} \text { Categorised by clinical investigators on this study using CT scan data grouped by the } \\
\text { AJCCC criteria. }\end{array}$} \\
\hline
\end{tabular}

Survival analysis. The median survival time in the whole study population was 10.0 months from diagnosis to death or last followup, ranging from 0 to 123.6 months. Age and gender were associated with longer survival; however, there was no clear association with other demographic variables (Table 2). Patients with the epithelioid subtype survived significantly longer than those presenting with biphasic or sarcomatoid histology (13.4 months $v s 7.2$ and 5.4 months respectively; $P<0.001)$. An ECOG status of 0 was associated with a marked improvement in survival (26.6 vs 9.8 months; $P=0.015$ ). Additional factors such as low NLR, normal WCC, normal albumin, normal haemoglobin and normal platelet counts were also associated with longer-term survival. Patients who had undergone an EPP had a median survival of 24.7 months (counted from diagnosis and 21.7 months from the date of surgery), whereas the median survival of patients who did not receive radical surgery was limited to 9.5 months. When modelled as a time-dependent variable unadjusted for other covariates, the effect of EPP on survival was significant $(\mathrm{HR}=0.41$ (0.30, 0.56); $P<0.001)$. Patients who received pemetrexed-based chemotherapy had a median survival of 15.8 months from diagnosis (11.4 months from treatment) compared with 10.4 months (6.1 months from treatment) on other chemotherapy regimens $(P=0.017$ from Cox model comparing time-dependent effects). Patients who received no chemotherapy had a median survival of 6.6 months from diagnosis. The EORTC prognostic score consistent with 'low-risk' conferred a survival advantage (14.2 vs 8.3 months; $P<0.001)$ in comparison to the 'high-risk' subgroup.

Multivariate analyses. Data from 557 patients were included in the multivariate analyses. For these analyses, only those factors with $P<0.20$ in the univariate analysis were considered (Table 3 ). CT staging was not included due to limitations associated with this modality.

Multivariate analyses showed increasing age ( $>70$ years) and male gender had poorer survival outcomes, while ECOG status was not an independent prognostic factor. Patients presenting with a tumour with negative calretinin expression had a two-fold greater mortality risk than patients with positive calretinin IHC (HR 2.13, $95 \%$ CI $1.50,3.02)$. High platelet counts $\left(\geqslant 400 \times 10^{9} 1^{-1}\right)$, and low haemoglobin were also associated with an increased risk of death (HR 1.39; 95\% CI 1.13, 1.70 and HR 1.27; 95\% CI 1.02, 1.58, respectively). Increasing NLR (on assessment as a continuous variable) was also independently associated with poor prognosis (HR 1.04; 95\% CI 1.02, 1.06). Patients who presented with nonepithelioid histological subtypes had a two-fold greater risk of mortality compared with epithelioid histology (HR 2.00; 95\% CI $1.62,2.48)$.
Table 2. Median survival time in months for patients diagnosed with malignant pleural mesothelioma compensated for occupational asbestos exposure in New South Wales, 2002-2009, by patient characteristics

\begin{tabular}{|c|c|c|}
\hline & $\begin{array}{l}\text { Median } \\
\text { survival in } \\
\text { months }\end{array}$ & $\begin{array}{l}\text { Difference } \\
\text { (Log-rank } \\
\text { P-value) }\end{array}$ \\
\hline \multicolumn{3}{|l|}{ Demographic characteristics } \\
\hline $\begin{array}{l}\text { Sex } \\
\text { Male } \\
\text { Female }\end{array}$ & $\begin{array}{c}9.9 \\
12\end{array}$ & $<0.001$ \\
\hline $\begin{array}{l}\text { Age at diagnosis } \\
<70 \text { years of age } \\
\geqslant 70 \text { years of age }\end{array}$ & $\begin{array}{r}13.5 \\
8.5\end{array}$ & $<0.001$ \\
\hline $\begin{array}{l}\text { Smoking status } \\
\text { Never smoker } \\
\text { Ex/current smoker }\end{array}$ & $\begin{array}{l}10 \\
10.6\end{array}$ & 0.99 \\
\hline $\begin{array}{l}\text { Asbestos exposure }^{\text {a }} \\
<18 \text { years of age at first asbestos exposure } \\
\geqslant 18 \text { years of age at first asbestos exposure } \\
<24 \text { years of cumulative asbestos exposure } \\
\geqslant 24 \text { years of cumulative asbestos exposure }\end{array}$ & $\begin{array}{r}10.9 \\
9.4 \\
10.4 \\
9.5\end{array}$ & $\begin{array}{l}0.09 \\
0.22\end{array}$ \\
\hline $\begin{array}{l}\text { Geographic location at the time of diagnosis } \\
\text { Major city } \\
\text { (Inner or outer) Regional/remote }\end{array}$ & $\begin{array}{r}10.6 \\
8.8\end{array}$ & 0.162 \\
\hline \multicolumn{3}{|l|}{ Clinical and pathological characteristics } \\
\hline $\begin{array}{l}\text { Calretinin expression } \\
\text { Positive expression } \\
\text { Negative expression }\end{array}$ & $\begin{array}{r}10.9 \\
5.5\end{array}$ & $<0.001$ \\
\hline $\begin{array}{l}\text { Clinical stage at diagnosis } \\
\text { Early stage disease (Stages X, I-II) } \\
\text { Late stage disease (Stages III-IV) }\end{array}$ & $\begin{array}{r}12.9 \\
8.4\end{array}$ & $<0.001$ \\
\hline $\begin{array}{r}\text { NLR } \\
<5 \\
\geqslant 5\end{array}$ & $\begin{array}{r}11.9 \\
7.5\end{array}$ & $<0.001$ \\
\hline $\begin{array}{l}\text { Haemoglobin (from baseline) } \\
<1 \mathrm{~g} \mathrm{dl}^{-1} \\
\geqslant 1 \mathrm{~g} \mathrm{dl}^{-1}\end{array}$ & $\begin{array}{r}16.4 \\
8.8\end{array}$ & $<0.001$ \\
\hline $\begin{array}{l}\text { Platelets }\left(\times 10^{9} \mathrm{I}^{-1}\right) \\
\quad<400 \\
\geqslant 400\end{array}$ & $\begin{array}{r}11.5 \\
7.2\end{array}$ & $<0.001$ \\
\hline $\begin{array}{l}\text { Albumin } \\
\geqslant 35 \mathrm{~g} \mathrm{dl}^{-1} \\
<35 \mathrm{~g} \mathrm{dl}^{-1}\end{array}$ & $\begin{array}{l}13 \\
6.7\end{array}$ & $<0.001$ \\
\hline $\begin{array}{l}\text { White cell count } \\
<8.3 \\
\geqslant 8.3\end{array}$ & $\begin{array}{r}12.9 \\
8.4\end{array}$ & $<0.001$ \\
\hline \multicolumn{3}{|l|}{ Tumour characteristics } \\
\hline $\begin{array}{l}\text { Histological subtype } \\
\text { Epithelioid } \\
\text { Non-epithelioid }\end{array}$ & $\begin{array}{r}13.3 \\
6.2\end{array}$ & $<0.001$ \\
\hline ECOG & & 0.015 \\
\hline $\begin{array}{l}0 \\
\geqslant 1\end{array}$ & $\begin{array}{r}27.4 \\
9.7\end{array}$ & \\
\hline EORTC & & $<0.0001$ \\
\hline $\begin{array}{l}\text { Low risk: } 0-2 \\
\text { High risk: } \geqslant 3\end{array}$ & $\begin{array}{c}14 \\
8.2\end{array}$ & \\
\hline \multicolumn{3}{|c|}{$\begin{array}{l}\text { Abbreviations: ECOG = Eastern Cooperative Oncology Group; EORTC = European Orga- } \\
\text { nisation for Research and Treatment of Cancer; NLR= neutrophil-lymphocyte ratio. } \\
\text { a Estimated using data of a patients' first age at asbestos exposure and occupational history. }^{\text {b Categorised by clinical investigators on this study using CT scan data grouped by the }} \\
\text { AJCCC criteria. }\end{array}$} \\
\hline
\end{tabular}

A landmark analysis of 721 patients was undertaken that compared survival in EPP and non-EPP patients from the start of the fourth month following diagnosis (when 44 of the 58 EPPs had been performed). This demonstrated a survival advantage for EPP $(\mathrm{HR}=0.42$ (95\% CI: 0.29-0.60); $P<0.001)$; independent of other variables (Figure 2).

Separately, we also analysed patients classified as goodprognosis according to the EORTC criteria (Curran et al, 1998). 
Table 3. Hazard rate ratios for patients diagnosed with malignant pleural mesothelioma compensated for occupational asbestos exposure in New South Wales, 2002-2009, $(n=557)$, by patient characteristics

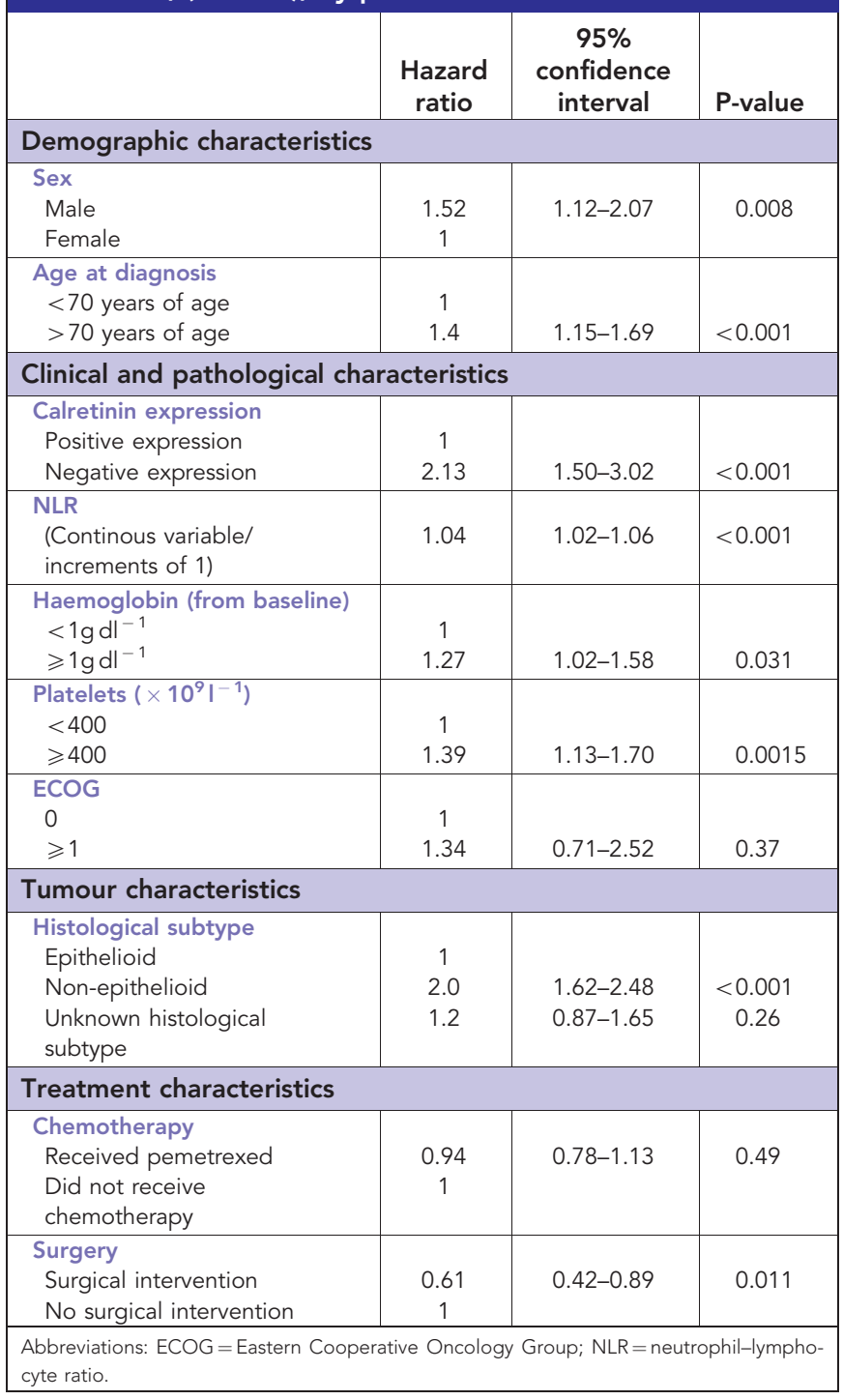

Of the 305 patients fulfilling EORTC criteria, 32 received EPP while 273 patients did not. The EPP group had a significantly reduced mortality risk $(\mathrm{HR}=0.49$ (95\% CI: $0.32,0.73 ; P<0.001$; Figure 3). Median survival in the group of patients who did not receive EPP was 13.3 months (range 0.2-109.6 months), with $29 \%$ surviving for $\geqslant 20$ months. In patients who did receive EPP, the median survival was 24.7 months from diagnosis (21.6 months from the date of surgery) and $66 \%$ survived $\geqslant 20$ months following diagnosis.

Logistic regression. One in four patients diagnosed with MPM survived at least twice as long as the median survival time. Early stage disease, positive calretinin expression, epithelioid subtype, younger age and a normal haemoglobin level were all independently associated with prolonged survival. In this group of 'long survivors', $66 \% \%$ received chemotherapy and 16\% had undergone radical surgery. It is noteworthy that a third of the group of long survivors did not receive any chemotherapy or radical surgery. Epithelioid histology, lower WCC and platelet counts, lower NLR and higher haemoglobin levels were more prominent in the longterm survivors ( $>20$ months) in a subgroup analysis of patients who did not receive any chemotherapy or radical surgery $(N=455)$.

Finally, we derived a PI to predict the probability of longerterm survival for MPM patients based on the variables analysed in this study (Figure 4). By summing the points across these factors, it was possible to predict the probability of an individual patient to survive for $>20$ months. For example, using the values in Figure 4 , a male patient ( 1 point), aged $70-79$ years ( 3 points), with epithelioid subtype ( 0 points), with a NLR of $\geqslant 10$ ( 2 points), had a total of 6 points, or a $22 \%$ probability of 20 month survival following a MPM diagnosis. Upon ROC analysis, the optimal cutpoint for the PI was determined (Supplementary Figure S1). Patients were defined as 'low risk' if the PI yielded a score of $\leqslant 5$, with a sensitivity and specificity of $76 \%$ and $62 \%$, respectively, for survival beyond 20 months. A $C$ statistic of 0.747 was noted, suggesting moderate performance for the PI. 'Highrisk' patients were associated with a median survival of 6.6 months (HR 2.4; c.f 16.6 months in the low-risk subgroup; $P<0.0001$; Figure 5A). A comparison of our PI with the EORTC prognostic model revealed better separation of good and poor prognosis using the PI. Furthermore, the application of the PI score to patients already separated into low- and high-risk subgroups by the EORTC score provided additional prognostic value with enhanced separation of the survival groups (Figure 5B). Conversely, the addition of the EORTC score to PI score did not provide any further improvement in prognostication. Upon analysis of variables instrumental in reallocation from high to low subgroups (and vice verse) between the EORTC and PI models, albumin, calretinin, NLR and age provided the greatest additional discriminatory information.

\section{DISCUSSION}

This series of patients with MPM who registered with the DDB reflects one of the largest series reported so far. All NSW people with asbestos exposure had access to DDB support without geographic, ethnic or financial restrictions, as long as their exposure had occurred in an occupational setting in NSW. As such, this series reflects a general MPM population with minimal selection bias.

Our study suggests that there are two distinct categories of patients with MPM. One with a rapid and fatal disease course, as is well recognised in the clinical literature, and a second group for whom survival is significantly longer. A significant proportion of the current series of patients (25\%) lived at least double the median survival time of 10.0 months, a finding consistent with previous reports (Vogelzang et al, 2003; Yan et al, 2009a). One-third of this group of long survivors did not receive any chemotherapy or radical surgery.

Prognostic factors and risk scores have typically been derived from populations of patients who are on clinical trials or in the small group of patients who have been well enough for radical surgery and who may not be representative of the general MPM population. The factors associated with longer-term survival in unselected MPM cohorts have not been extensively studied. Previous analyses have demonstrated the role of gender, age and histological subtype as prognostic factors (Antman et al, 1988; Musk et al, 2011), but a lack of accurate clinical, pathological and treatment data have precluded more comprehensive analyses. We have been able to obtain most of these data for the patients included in our population-based series. Our results confirm the prognostic value of demographic variables (age and gender) and clinical and laboratory factors (histological subtype, NLR, albumin, haemoglobin and platelet counts). We have also collected evidence for factors where significance was unclear, namely calretinin 


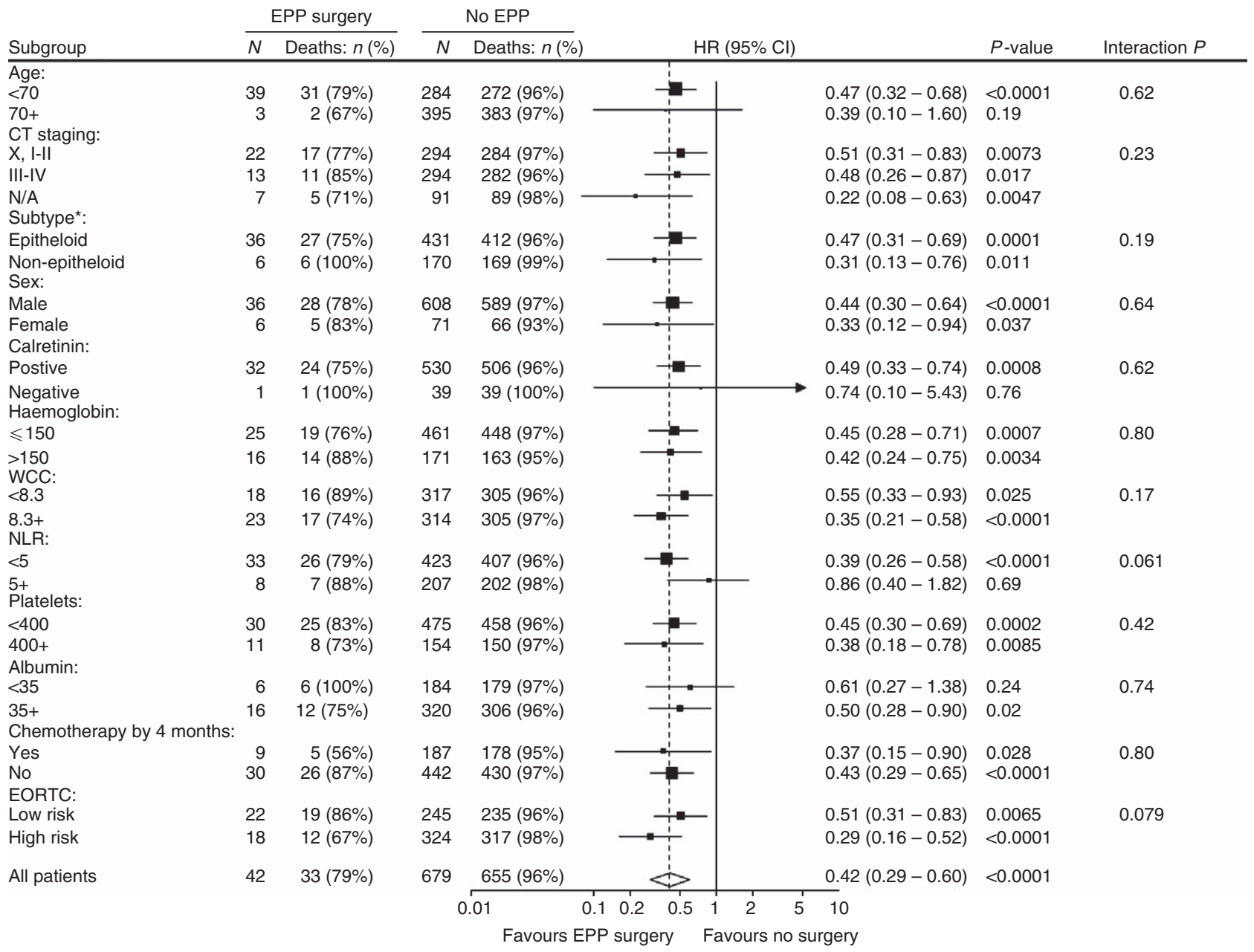

Figure 2. Four-month landmark analysis: effect of EPP surgery within 4 months on survival after 4 months. Analyses included up to 721 patients alive at 4 months. *Unknown group $(N=78)$ excluded from analysis as zero patients in this category underwent surgery.

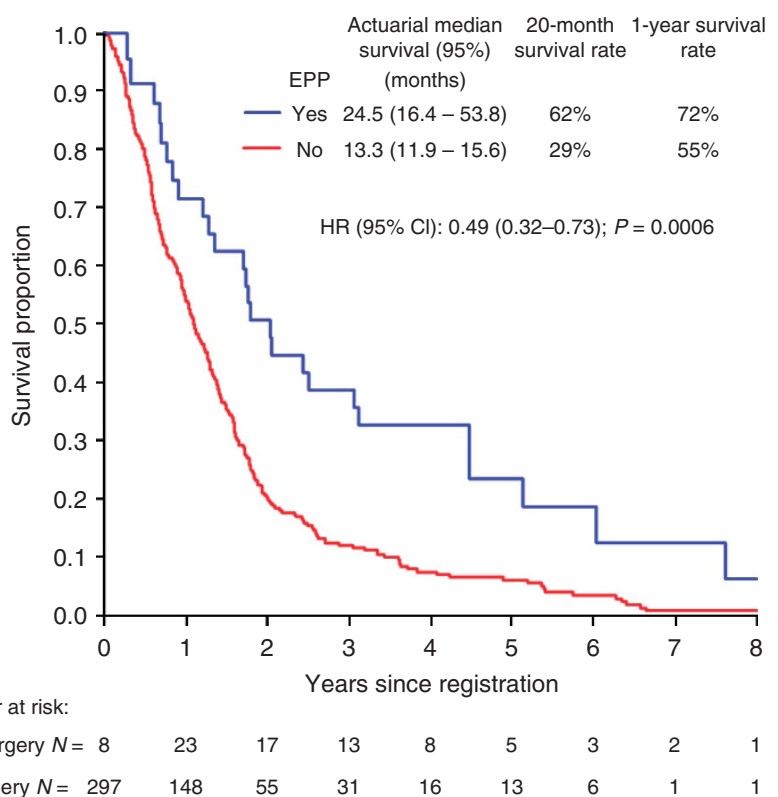

Figure 3. Extended Kaplan-Meier survival curves, stratified by time-varying EPP surgery status in good prognosis group (i.e., EORTC = low risk, $N=305$ ). Hazard ratios and $P$-values are from a Cox regression model with a time-varying covariate. expression, the effects of chemotherapy and radical surgery. In addition, we have also developed a prediction tool that may assist clinicians in identifying MPM patients likely to experience longerterm survival.

Calretinin expression has previously been found to be associated with prolonged survival in selected surgical series of MPM patients (Kao et al, 2011). To our knowledge, this study presents the first evidence for an important association between prognosis and calretinin expression in a large, unselected MPM population. The association between positive staining and prolonged survival is of the same magnitude as the association between epitheloid subtype and prolonged survival in multivariate analysis. Patients with no calretinin expression had poor survival (median survival time of 5.5 months). However, it should be noted that the size of this specific group was relatively small (8.6\% of patients tested). This observation raises the question whether calretinin may be involved in tumour growth. Recent data suggest that there is a role for calretinin in maintaining the viability and proliferation of mesothelioma cells in vitro and that downregulation of this target occurs when apoptosis pathways become activated (Blum and Schwaller, 2013). Calretinin expression may also be seen as a surrogate marker for tumour differentiation (Takeshima et al, 2010).

Our series shows that $41 \%$ of patients received chemotherapy. This did not differ between major cities and regional/remote locations. The percentage of patients receiving chemotherapy is comparable to another population based study in Europe 
demonstrating chemotherapy usage of $36 \%$ during a similar period (Damhuis et al, 2012). Rates were lower still in the UKbased series where, although $37 \%$ were considered suitable for

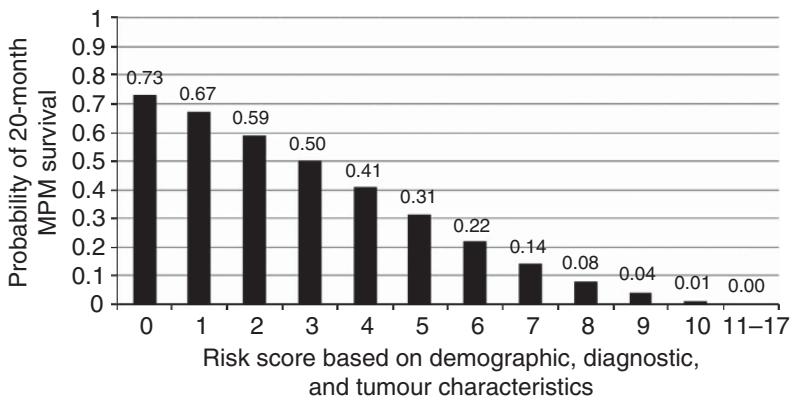

\begin{tabular}{|c|c|}
\hline & Points \\
\hline \multicolumn{2}{|c|}{ Demographic characteristics } \\
\hline $\begin{array}{l}\text { Sex } \\
\text { Mela } \\
\text { Felame }\end{array}$ & $\begin{array}{l}1 \\
0\end{array}$ \\
\hline $\begin{array}{l}\text { Age at diagnosis } \\
41-49 \\
50-59 \\
60-69 \\
70-79 \\
80-89 \\
90-92\end{array}$ & $\begin{array}{l}0 \\
1 \\
2 \\
3 \\
4 \\
5\end{array}$ \\
\hline \multicolumn{2}{|c|}{ Clinical and pathological characteristics } \\
\hline $\begin{array}{l}\text { Calretinin expression } \\
\text { Positive expression } \\
\text { Negative expression }\end{array}$ & $\begin{array}{l}0 \\
3\end{array}$ \\
\hline $\begin{array}{l}\text { NLR } \\
<5 \\
5 \leqslant 10 \\
\geqslant 10\end{array}$ & $\begin{array}{l}0 \\
0 \\
2\end{array}$ \\
\hline $\begin{array}{l}\text { Platelets }\left(\times 10^{9} \mathrm{I}^{-1}\right) \\
\quad<400 \\
>400\end{array}$ & $\begin{array}{l}0 \\
1\end{array}$ \\
\hline $\begin{array}{l}\text { Albumin } \\
\quad<35 \mathrm{~g} \mathrm{dl}^{-1} \\
\geqslant 35 \mathrm{~g} \mathrm{dl}^{-1}\end{array}$ & $\begin{array}{l}1 \\
0\end{array}$ \\
\hline $\begin{array}{l}\text { White cell count } \\
<8.3 \\
\geqslant 8.3\end{array}$ & $\begin{array}{l}0 \\
1\end{array}$ \\
\hline Tumour characteristi & \\
\hline $\begin{array}{l}\text { Histological subtype } \\
\text { Epithelioid } \\
\text { Non-epithelioid } \\
\text { Unknown }\end{array}$ & $\begin{array}{l}0 \\
3 \\
1\end{array}$ \\
\hline
\end{tabular}

Figure 4. Probability of 20-month survival following a MPM diagnosis using risk scores based on a patient's demographic, diagnosticand tumour characteristics. chemotherapy, $52 \%$ of patients declined its use (Chapman et al, 2008). We do, however, note an increase in chemotherapy usage after the addition of pemetrexed to the Australian Pharmaceutical Benefits Scheme (38.9->48.8\%). Our data confirm that pemetrexed-based chemotherapy is associated with a survival benefit. Vogelzang et al (2003) demonstrated that administration of pemetrexed in combination with cisplatin was responsible for a significant (3-month improvement) in overall survival. In our study, a 5-month survival difference was recorded when patients with and without pemetrexed-containing regimens were compared.

EPP, the en bloc resection of the pleura and lung, is typically reserved for a group of highly selected medically fit patients with lower volume, epithelioid MPM. Retrospective and non-randomised prospective analyses of EPP studies in MPM have produced inconsistent results with survival, mortality and morbidity rates varying markedly between studies and centres (Weder et al, 2004; Yan et al, 2009b; Lang-Lazdunski et al, 2012). The prospective MARS feasibility study (Treasure et al, 2011), attempting to compare EPP in combination with chemotherapy and radiotherapy to chemotherapy alone, noted a 5-month decline in overall survival in patients undergoing EPP. However, the significant recruitment difficulties, patient crossover (only 16 of the 24 patients randomised to EPP underwent surgery) and the high operative mortality (15.8\%) has complicated the interpretation of the study results and induced a lively discussion about the role of EPP in MPM (Rusch, 2009; Weder et al, 2011). Theoretically, EPP remains the favoured surgical procedure for optimal cytoreduction (Rice et al, 2011), but in recent years a move to the less aggressive extended pleurectomy/decortication (also associated with median survivals of over 30 months) has occurred owing to concerns that EPP may be associated with increased morbidity/mortality as well as a reduction in the quality of life (Bolukbas et al, 2011; Friedberg et al, 2012; Cao et al, 2014).

In our series, $6 \%$ of patients underwent EPP. This percentage is markedly lower than in previously reported US single institution series (Flores et al, 2007). Although palliative surgical procedures such as pleurectomy and/or decortications $(\mathrm{P} / \mathrm{D})$ were noted in the files of patients in our series, we have not included these data in our report. Absence of standardisation and variability in reporting were the main reasons for this decision. In general, however, the performance of $\mathrm{P} / \mathrm{D}$ within NSW has been primarily for palliative intent. In this series, EPP patients had a survival benefit, and this benefit remained unaffected when adjustments were made for favourable prognostic factors present at diagnosis. This finding differs from a recent study in 1365 Italian patients diagnosed with MPM, where the survival advantage noted in patients receiving EPP disappeared after restricting the analyses to patients with
A

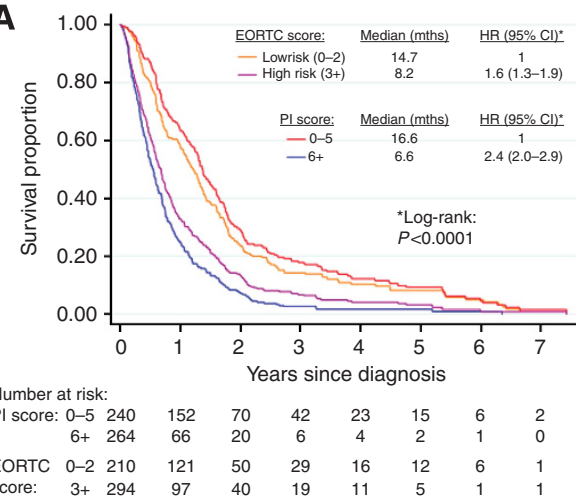

B

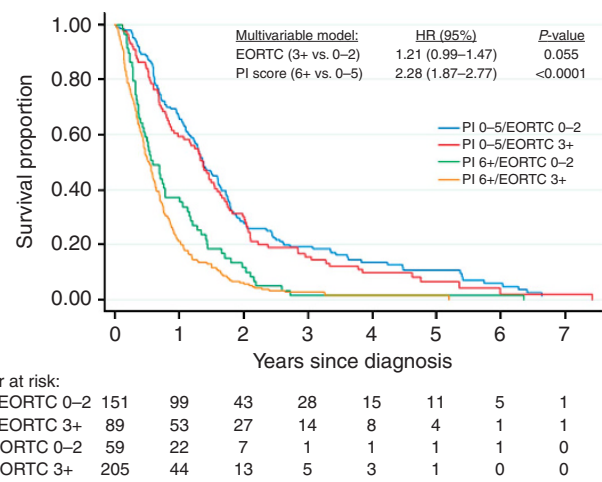

Figure 5. (A) Kaplan-Meier curves demonstrating survival according to prognostic indices (PI Score-0-5 vs $6+$ ) and EORTC score (Low risk0-2 vs High risk-3+). (B) Survival by PI cross-classification. 
favourable factors (Bovolato et al, 2014). The inconsistency between the Italian results and our study can be explained by two factors. First, the percentage of patients undergoing EPP in our study was lower than the Italian cohort. Second, in our study one single surgeon completed 57 of the 58 EPPs, suggesting that expertise and volume-outcome associations are important. This is underlined by a 90 -day mortality of $3.5 \%$, which is markedly lower than the mortality in the MARS feasibility trial and meta-analysis (Cao et al, 2014). The mortality percentage in this series is consistent with the percentage seen in other high-volume centres (Burt et al, 2014). Overall, our findings suggest that, in experienced hands, EPP is a safe and potentially advantageous intervention in a highly selected group of patients.

A potential limitation of our study is that more patients were categorised as having early stage disease compared with previous studies (Vogelzang et al, 2003). Clinical stage is most accurately determined when PET scan or surgical staging data are available (Schouwink et al, 2003). However, these interventions were only performed in a minority of patients. Instead, clinical stage as determined by CT was available for $85 \%$ of the study population. As a result, late stage disease (stages III-IV) in this study was defined as bulky pleural, nodal or metastatic disease, rather than an accurate TNM status. This is unavoidable in a populationbased study with non-uniform diagnostic imaging and sometime lack of tertiary expertise. To eliminate this potential inaccuracy, we have not included CT staging in our multivariate analysis or the PI.

We can only speculate about the reasons behind prolonged survival of patients who did not receive any active treatment. Although these patients were more likely to have epithelioid histology and 'normal' haemoglobin, white cell and platelet counts, additional factors may have played a role. In a previous study, we have pointed to the potential prognostic significance of ERCC1 and PLK1. In addition, miRNAs are thought to have an important role (Kao et al, 2013; Kirschner et al, 2013; Linton et al, 2014), while biomarkers such as mesothelin and osteopontin may also influence survival (Grigoriu et al, 2007; Roe et al, 2008). Although these biomarkers could not be assessed in this series, the performance of further studies with existing and new prognostic markers and their incorporation in prognostic scoring systems remain a priority.

Finally, we have presented a tool to select patients for intensive therapy approaches by combining prognostic factors. The tool includes two markers not included in previously published riskprediction tools for MPM (Curran et al, 1998; Herndon et al, 1998), namely, NLR and calretinin expression. We have not included ECOG performance status in our model as it lacked significance on multivariate analysis. Furthermore, the inclusion of a variable assessing the probability of accurate histological diagnosis is of lesser value in the modern era as guideline-driven immunohistochemical testing has eliminated much diagnostic uncertainty.

We have added newly identified factors to established prognostic factors and developed a PI that seems to have additional prognostic value over the existing EORTC model. In order to further assess this model, validation is now warranted in a large independent series of patients. Although bias-corrected estimates on the training samples can be calculated using bootstrapping, in data sets with large sample sizes and event numbers (as in our series where $96 \%$ of patients had died of the 551 used to develop the risk score), optimism in performance measures has been shown to be small and apparent estimates of model performance are attractive because of their stability (Steyerberg et al, 2001). As such, bootstrapping was not indicated for our final model.

In conclusion, this study has confirmed the role of a range of factors known to be associated with longer-term survival in a real-world MPM population. We also found that calretinin expression is strongly associated with survival outcomes. EPP and pemetrexed-containing chemotherapy seem also capable of inducing a survival benefit that remains distinguishable after correction for 'good prognosis' factors. Finally, we have presented a risk score that may assist with the appropriate selection of patients for intensive (combined modality) therapy approaches.

\section{ACKNOWLEDGEMENTS}

Thanks to Giles Yates and Kirsty Hannaford Turner from the NSW DDB. Thanks to the many medical oncologists, radiation oncologists, surgeons, thoracic physicians and general practitioners across NSW who assisted us in the collection of patient data, in particular Dr Brian McCaughan and Dr Philip Clingan. Thanks to Nicola Armstrong from the University of Sydney for additional statistical input.

\section{CONFLICT OF INTEREST}

Anthony Linton is supported by the Biaggio Signorelli Foundation. Janette Vardy and the Asbestos Diseases Research Institute are supported by the Cancer Institute NSW. The remaining authors declare no conflict of interest.

\section{REFERENCES}

Abakay A, Komek H, Abakay O, Palanci Y, Ekici F, Tekbas G, Tanrikulu AC (2013) Relationship between 18 FDG PET-CT findings and the survival of 177 patients with malignant pleural mesothelioma. Eur Rev Med Pharmacol Sci 17(9): 1233-1241.

Antman K, Shemin R, Ryan L, Klegar K, Osteen R, Herman T, Lederman G, Corson J (1988) Malignant mesothelioma: prognostic variables in a registry of 180 patients, the Dana-Farber Cancer Institute and Brigham and Women's Hospital experience over two decades, 1965-1985. J Clin Oncol 6(1): 147-153.

Australian-Bureau-of-Statistics (2011) Australian Statistical Geography Standard (ASGS) Volume 5, Remoteness Areas Commonwealth of Australia: Canberra, Australia.

Blum W, Schwaller B (2013) Calretinin is essential for mesothelioma cell growth/survival in vitro: a potential new target for malignant mesothelioma therapy? Int J Cancer 133(9): 2077-2088.

Bolukbas S, Manegold C, Eberlein M, Bergmann T, Fisseler-Eckhoff A, Schirren J (2011) Survival after trimodality therapy for malignant pleural mesothelioma: radical Pleurectomy, chemotherapy with Cisplatin/ Pemetrexed and radiotherapy. Lung Cancer 71(1): 75-81.

Bovolato P, Casadio C, Bille A, Ardissone F, Santambrogio L, Ratto GB, Garofalo G, Bedini AV, Garassino M, Porcu L, Torri V, Pastorino U (2014) Does surgery improve survival of patients with malignant pleural mesothelioma?: a multicenter retrospective analysis of 1365 consecutive patients. J Thorac Oncol 9(3): 390-396.

Burt BM, Cameron RB, Mollberg NM, Kosinski AS, Schipper PH, Shrager JB, Vigneswaran WT (2014) Malignant pleural mesothelioma and the Society of Thoracic Surgeons Database: an analysis of surgical morbidity and mortality. J Thorac Cardiovasc Surg 148(1): 30-35.

Cao C, Tian D, Park J, Allan J, Pataky KA, Yan TD (2014) A systematic review and meta-analysis of surgical treatments for malignant pleural mesothelioma. Lung Cancer 83(2): 240-245.

Cao CQ, Yan TD, Bannon PG, McCaughan BC (2010) A systematic review of extrapleural pneumonectomy for malignant pleural mesothelioma. $J$ Thorac Oncol 5(10): 1692-1703.

Chahinian AP, Pass H (2000) Malignant mesothelioma. In Cancer Medicine, Holland JC, Frei E (eds) 5th edn, pp 1293-1312. BC: Decker Inc: Ontario, Canada. 
Chapman A, Mulrennan S, Ladd B, Muers MF (2008) Population based epidemiology and prognosis of mesothelioma in Leeds, UK. Thorax 63(5): 435-439.

Curran D, Sahmoud T, Therasse P, van Meerbeeck J, Postmus PE, Giaccone G (1998) Prognostic factors in patients with pleural mesothelioma: the European Organization for Research and Treatment of Cancer experience. J Clin Oncol 16(1): 145-152.

Damhuis RA, Schroten C, Burgers JA (2012) Population-based survival for malignant mesothelioma after introduction of novel chemotherapy. Eur Respir J 40(1): 185-189.

Fennell DA, Parmar A, Shamash J, Evans MT, Sheaff MT, Sylvester R, Dhaliwal K, Gower N, Steele J, Rudd R (2005) Statistical validation of the EORTC prognostic model for malignant pleural mesothelioma based on three consecutive phase II trials. J Clin Oncol 23(1): 184-189.

Flores RM, Pass HI, Seshan VE, Dycoco J, Zakowski M, Carbone M, Bains MS, Rusch VW (2008) Extrapleural pneumonectomy versus pleurectomy/decortication in the surgical management of malignant pleural mesothelioma: results in 663 patients. J Thorac Cardiovas Surg 135(3): 620-626e3.

Flores RM, Zakowski M, Venkatraman E, Krug L, Rosenzweig K, Dycoco J, Lee C, Yeoh C, Bains M, Rusch V (2007) Prognostic factors in the treatment of malignant pleural mesothelioma at a large tertiary referral center. J Thorac Oncol 2(10): 957-965.

Freedman LS, Graubard BI, Schatzkin A (1992) Statistical validation of intermediate endpoints for chronic diseases. Stat Med 11(2): 167-178.

Friedberg JS, Culligan MJ, Mick R, Stevenson J, Hahn SM, Sterman D, Punekar S, Glatstein E, Cengel K (2012) Radical pleurectomy and intraoperative photodynamic therapy for malignant pleural mesothelioma. Ann Thorac Surg 93(5): 1658-1665; discussion 1665-7.

Grigoriu BD, Scherpereel A, Devos P, Chahine B, Letourneux M, Lebailly P, Gregoire M, Porte H, Copin MC, Lassalle P (2007) Utility of osteopontin and serum mesothelin in malignant pleural mesothelioma diagnosis and prognosis assessment. Clin Cancer Res 13(10): 2928-2935.

Hanley JA, McNeil BJ (1982) The meaning and use of the area under a receiver operating characteristic (ROC) curve. Radiology 143(1): 29-36.

Helland A, Solberg S, Brustugun OT (2012) Incidence and survival of malignant pleural mesothelioma in norway: a population-based study of 1686 cases. J Thorac Oncol 7(12): 1858-1861.

Herndon JE, Green MR, Chahinian AP, Corson JM, Suzuki Y, Vogelzang NJ (1998) Factors predictive of survival among 337 patients with mesothelioma treated between 1984 and 1994 by the Cancer and Leukemia Group B. Chest 113(3): 723-731.

Hosmer D, Lemeshow S (2000) Applied Logistic Regression. 2nd edn. John Wiley \& Sons, Inc.: New York, NY, USA.

Kao SC, Klebe S, Henderson DW, Reid G, Chatfield M, Armstrong NJ, Yan TD, Vardy J, Clarke S, van Zandwijk N, McCaughan B (2011) Low calretinin expression and high neutrophil-to-lymphocyte ratio are poor prognostic factors in patients with malignant mesothelioma undergoing extrapleural pneumonectomy. J Thorac Oncol 6(11): 1923-1929.

Kao SC, Lee K, Klebe S, Henderson D, McCaughan B, Vardy J, Clarke S, van Zandwijk N (2013) Excision repair cross complementation group 1 and thymidylate synthase expression in patients with mesothelioma. Clin Lung Cancer 14(2): 164-171.

Kao SC, Pavlakis N, Harvie R, Vardy JL, Boyer MJ, van Zandwijk N, Clarke SJ (2010) High blood neutrophil-to-lymphocyte ratio is an indicator of poor prognosis in malignant mesothelioma patients undergoing systemic therapy. Clin Cancer Res 16(23): 5805-5813.

Kirschner MB, Cheng YY, Kao SC, McCaughan B, van Zandwijk N, Reid G (2013) Elevated tumour expression of miR-210 is associated with short survival in malignant pleural mesothelioma patients undergoing extrapleural pneumonectomy. In 15th World Conference on Lung Cancer Vol. 8, p Supp 2: S344 (M014.07) Journal Thoracic Oncology: Sydney, Australia.

Lang-Lazdunski L, Bille A, Lal R, Cane P, McLean E, Landau D, Steele J, Spicer J (2012) Pleurectomy/decortication is superior to extrapleural pneumonectomy in the multimodality management of patients with malignant pleural mesothelioma. J Thorac Oncol 7(4): 737-743.

Linton A, Cheng YY, Griggs K, Kirschner MB, Gattani S, Srikaran S, Chuan-Hao Kao S, McCaughan BC, Klebe S, van Zandwijk N, Reid G (2014) An RNAi-based screen reveals PLK1, CDK1 and NDC80 as potential therapeutic targets in malignant pleural mesothelioma. Br J Cancer 110(2): 510-519.
Linton A, Vardy J, Clarke S, van Zandwijk N (2012) The ticking time-bomb of asbestos: Its insidious role in the development of malignant mesothelioma. Crit Rev Oncol Hematol 84(2): 200-212.

Meniawy TM, Creaney J, Lake RA, Nowak AK (2013) Existing models, but not neutrophil-to-lymphocyte ratio, are prognostic in malignant mesothelioma. Br J Cancer 109(7): 1813-1820.

Murphy S, Probert G, Anderson J, Pollock S, Taylor I, Clague H, Sridharan K (2013) Malignant mesothelioma, hypoalbuminaemia and the effect of carboplatin/pemetrexed on survival. Clin Oncol (R Coll Radiol) 25(12): 713-718.

Musk AW, Olsen N, Alfonso H, Reid A, Mina R, Franklin P, Sleith J, Hammond N, Threlfall T, Shilkin KB, de Klerk NH (2011) Predicting survival in malignant mesothelioma. Eur Respir J 38(6): 1420-1424.

Rice D, Rusch V, Pass H, Asamura H, Nakano T, Edwards J, Giroux DJ, Hasegawa S, Kernstine KH, Waller D, Rami-Porta R (2011) Recommendations for uniform definitions of surgical techniques for malignant pleural mesothelioma: a consensus report of the international association for the study of lung cancer International staging committee and the international mesothelioma interest group. J Thorac Oncol 6(8): 1304-1312.

Roe OD, Creaney J, Lundgren S, Larsson E, Sandeck H, Boffetta P, Nilsen TI, Robinson B, Kjaerheim K (2008) Mesothelin-related predictive and prognostic factors in malignant mesothelioma: a nested case-control study. Lung Cancer 61(2): 235-243.

Rusch VW (2009) The MARS trial: resolution of the surgical controversies in mesothelioma? J Thorac Oncol 4(10): 1189-1191.

Schouwink JH, Schultze Kool L, Rutgers EJ, Zoetmulder FAN, van Zandwijk N, v.d. Vijver MJ, Baas P (2003) The value of chest computer tomography and cervical mediastinoscopy in the preoperative assessment of patients with malignant pleural mesothelioma. Ann Thorac Surg 75(6): 1715-1718.

Snapinn SM, Jiang Q, Iglewicz B (2005) Illustrating the impact of a timevarying covariate with an extended Kaplan-Meier estimator. Am Stat 59(4): 301-307.

Steyerberg EW, Harrell Jr FE, Borsboom GJ, Eijkemans MJ, Vergouwe Y, Habbema JD (2001) Internal validation of predictive models: efficiency of some procedures for logistic regression analysis. J Clin Epidemiol 54(8): 774-781.

Sullivan LM, Massaro JM, D’Agostino Sr RB (2004) Presentation of multivariate data for clinical use: the Framingham Study risk score functions. Stat Med 23(10): 1631-1660.

Takeshima Y, Inai K, Ishikawa Y, Oka T, Hiroshima K (2010) The trial of differentiation grading of epithelioid mesothelioma with reference to its clinicopathological significance (Abstr P10-1). In: 10th International Conference of the International Mesothelioma Interest Group, p 175. Available at: http://imig.org/wp-content/uploads/2011/01/ IMIG2010Abstractfinal101227.pdf. Accessed 28 July 2014.

Treasure T, Lang-Lazdunski L, Waller D, Bliss JM, Tan C, Entwisle J, Snee M, O'Brien M, Thomas G, Senan S, O'Byrne K, Kilburn LS, Spicer J, Landau D, Edwards J, Coombes G, Darlison L, Peto J (2011) Extra-pleural pneumonectomy versus no extra-pleural pneumonectomy for patients with malignant pleural mesothelioma: clinical outcomes of the Mesothelioma and Radical Surgery (MARS) randomised feasibility study. Lancet Oncol 12(8): 763-772.

Vogelzang NJ, Rusthoven JJ, Symanowski J, Denham C, Kaukel E, Ruffie P, Gatzemeier U, Boyer M, Emri S, Manegold C, Niyikiza C, Paoletti P (2003) Phase III study of pemetrexed in combination with cisplatin versus cisplatin alone in patients with malignant pleural mesothelioma. J Clin Oncol 21(14): 2636-2644.

Weder W, Kestenholz P, Taverna C, Bodis S, Lardinois D, Jerman M, Stahel RA (2004) Neoadjuvant chemotherapy followed by extrapleural pneumonectomy in malignant pleural mesothelioma. J Clin Oncol 22(17): 3451-3457.

Weder W, Stahel RA, Baas P, Dafni U, de Perrot M, McCaughan BC, Nakano T, Pass HI, Robinson BWS, Rusch VW, Sugarbaker DJ, van Zandwijk N (2011) The MARS feasibility trial: conclusions not supported by data. Lancet Oncol 12(12): 1093-1094.

Yan TD, Boyer M, Tin MM, Sim J, Kennedy C, McLean J, Bannon PG, McCaughan BC (2009a) Prognostic features of long-term survivors after surgical management of malignant pleural mesothelioma. Ann Thorac Surg 87(5): 1552-1556.

Yan TD, Boyer M, Tin MM, Wong D, Kennedy C, McLean J, Bannon PG, McCaughan BC (2009b) Extrapleural pneumonectomy for malignant pleural mesothelioma: outcomes of treatment and prognostic factors. J Thorac Cardiovasc Surg 138(3): 619-624. 
Yan TD, Cao CQ, Boyer M, Tin MM, Kennedy C, McLean J, Bannon PG, McCaughan BC (2011) Improving survival results after surgical management of malignant pleural mesothelioma: an Australian institution experience. Ann Thorac Cardiovasc Surg 17(3): 243-249.
This work is published under the standard license to publish agreement. After 12 months the work will become freely available and the license terms will switch to a Creative Commons AttributionNonCommercial-Share Alike 3.0 Unported License.

Supplementary Information accompanies this paper on British Journal of Cancer website (http://www.nature.com/bjc) 